\title{
The Status of Internal Controls in Fast Moving Small Medium and Micro Consumer Goods Enterprises within the Cape Peninsula
}

\author{
Luyolo Siwangaza \\ Yolande Smit \\ Juan-Pierré Bruwer \\ Faculty of Business, Cape Peninsula University of Technology, \\ P.0.Box 625, Cape Town, 8000, South Africa, Email: Siwangazal@webmail.co.za \\ Wilfred I. Ukpere \\ Department of Industrial Psychology and people Management, \\ University of Johannesburg, Johannesburg, Gauteng South Africa, Email: wiukpere@uj.ac.za
}

Doi:10.5901/mjss.2014.v5n10p163

\begin{abstract}
South African Small Medium and Micro Enterprises (SMMEs) play an important role in terms of stimulating the national economy. Despite the aforementioned, prior research shows that the failure rate of these entities is amongst one of the highest in the world, which is believed to be caused by economic factors. Several economic factors which impact on SMME sustainability have subsequently been researched and identified. As a result, SMME sustainability has received attention from the national government in recent times. One of economic factors which have been perceived by the authors as a major contributor to the high SMME failure rate is the lack of internal controls. Ultimately the responsibilities to both implement internal control frameworks and maintain all internal controls, rests with the management of an organisation. In essence, it can be said that a business is uncontrollable when it is essentially unmanageable. With the absence of adequate internal controls, an environment is created where an organisation is susceptible to all kinds of detrimental risks and, if these risks are not taken care of on time, the overall sustainability of the organisation could be negatively affected, which may lead in imminent failure. The main objective of this study was to determine the degree to which the implementation of an adequate system of internal control can help improve SMME sustainability. The research that was conducted was empirical in nature and fell within the ambit of the positivistic research paradigm. Questionnaires were administered and distributed to 110 owners and/or managers of SMMEs (SMME leaders) that operate within the fast moving consumer goods industry, situated in the Cape Peninsula. Based on the findings, it is obvious that most of the SMMEs do have a variety of internal controls, as prescribed by formal internal control frameworks but their support in terms of SMMEs sustainability were quite limited.
\end{abstract}

Keywords: SMMEs, sustainability, internal control, internal control framework, risk, South Africa.

\section{Introduction}

It is an undisputable fact that SMMEs play an important role in the South African economy. According to Kesper (2000) SMMEs are deemed as economic vehicles which should be developed to aid in the creation of jobs, the stimulation of the national economy and poverty alleviation. The vitality of SMMEs are put in perspective when emphasis is placed on the phenomenon that in the City of Cape Town alone, SMMEs are believed to be responsible for generating up to $50 \%$ of the City's total business transactions, which accounts for up to $40 \%$ of formal local employment (Hayes, 2001). Hence the significance of SMMEs, particularly pertaining to the development of their sustainability, in the South African economy, cannot be underestimated. Kesper (2000) makes mention that majority of South African SMMEs, especially in the retail sector, are informally classified as either micro enterprises (i.e. 'smallish' enterprises that have been in existence for at least 3 years) or survivalist enterprises (i.e. 'smallish' enterprises that have been in existence for less than 3 years).

Stemming from the above, Solomon (2004) asserts that one of the key reasons why SMME leaders start-up their respective SMMEs is mainly for survival purposes. In similar vein, Mutezo (2005) expressed the view that SMME leaders are mostly concerned about sales and profits generated more than any other aspect of their respective businesses. In a study by UCT (2010) it was found that necessity-turned-entrepreneurs (i.e. SMME leaders who started-up their respective 
SMMEs, purely to make a living), increased from $21 \%$ during the course of 2009 to $33 \%$ in 2010 . When the latter is taken into consideration with the current economic landscape of South Africa (Bruwer, Masama, Mgidi, Myezo, Ngayi, Nzuza, Phangwa, Sibanyoni \& Va, 2013), it is not surprising that the bulk of entrepreneurs are regarded as necessity entrepreneurs. Hence, it can be argued that such SMME leaders will find it difficult to survive in an anything but free spirited economic environment as they will not necessarily place emphasis on SMME development, but rather SMME profitability - eventually resulting in business failure. According to Naidoo (2007) SMMEs fail due to the lack of managerial skills, which is seriously needed by SMME leaders. In order to effectively manage the functional areas of a SMME, it is vital for SMME leaders to have critical managerial skills (i.e. skills which entail planning, organising, directing and controlling) and operational skills (i.e. skills to make business operations to function smoothly on a daily basis) (Solomon, 2004). When SMME leaders possess these skills it will become easy for them to respond to business risks that are detriment to their respective SMMEs' sustainability. In order to respond to the latter events effectively, the implementation of an adequate system of internal controls is non-negotiable.

Campbell and Hartcher (2003) assert that small businesses are known for having weak internal controls, as majority of these entities view the implementation of an adequate system of internal controls as a costly exercise. The latter view is further supported by Jackson and Stent (2007) who state that a major limitation of implementing proper internal controls is that most SMMEs follow a cost-benefit-approach. This approach entails that SMME leaders weigh the costs of implementing a system of internal controls against the potential benefits that can derived from having it implemented. Inescapably this approach, more often than not, will result in inadequate internal controls to be implemented and, consequently, creating a business environment that is susceptible to unwarranted risks. Regrettably if these risks surfaces in SMMEs, the overall sustainability of these SMMEs may be in jeopardy. As a result, the authors are of the assumption that the sustainability of SMMEs is adversely influenced by the utilisation of inadequate internal controls.

\section{Problem Statement}

SMMEs play a significant role in the economic and social development of South Africa. Despite their importance to the South African economy, there is still a large number of SMMEs that fail. The lack of managerial and operational skills of owners and/or managers of these business entities are one of the key factors which lead to SMMEs' failures. These factors, among others, have a direct effect on how a business is managed and internally controlled. No doubt, when a business cannot be managed, it cannot be controlled, which adversely affects the implementation of an adequate system(s) of internal controls. The problem therefore, is that SMMEs are unsustainable owing to inadequate use of effective internal controls.

\subsection{Research questions}

The above statement led to the following research question:

- How could the implementation of an adequate system of internal controls contribute to the sustainability of SMMEs?

- How are SMME owners and/or managers aware of the different types of internal controls?

- To what extent are these internal controls implemented in SMMEs?

- What factors prevent SMME owners and/or managers from implementing an adequate system of internal control?

- What evaluation/monitoring measures are in place in SMMEs, to determine the effectiveness of the implemented internal controls?

\subsection{Research objectives}

The following research objectives were formulated in view of the research questions identified above:

- To establish how the implementation of an adequate system of internal controls could contribute to the sustainability of SMMEs?

- To determine the awareness level of SMMEs management of internal controls and its framework,

- To determine whether most SMMEs implement and utilise internal controls system,

- To identify barriers that may prevent SMMEs from implementing an adequate system of internal controls,

- To establish whether existing internal controls inside SMMEs are adequately evaluated for effectiveness. 


\subsection{Paper outline}

The remaining part of this paper contains the literature review of South African SMMEs and their sustainability, factors influencing the sustainability of SMMEs in SA and internal control frameworks, amongst others. Thereafter, the research design and methodology for this study is discussed, and followed by a discussion of the findings from the collated data. This is followed by the conclusion based on the findings of the study.

\subsection{Literature Review: History of South African SMMEs}

According to the National Small Business Act No. 102 of 1996 a SMME is defined as a separate and distinct business entity, which is managed by one or more owner(s), which predominantly conducts its business in any sector and/or subsector of the national economy (South Africa, 1996; South Africa, 2004). Furthermore, the Department of Trade and Industry (2007) mention that SMMEs, in South Africa, can formally be categorised, in terms of their size, as micro enterprises, very small enterprises, small enterprises and/or medium enterprises, by making use of three categorisation criteria, namely the number of full-time employees employed, the annual sales made and the gross asset value, excluding fixed assets. Both Bruwer (2010), Smit and Watkins (2012) observe that the concept of SMMEs was formally introduced by the South African government to the national economy, with the main intention of creating jobs, alleviating poverty and stimulating the national economy. To achieve these latter objectives, Berry, Von Blottnits, Cassim, Kesper, Rajaratnam and Van Seventer (2002) note that SMMEs have been actively promoted by government, since 1996. The latter statement is confirmed by Bruwer et al. (2013) who state that the South African government has given a considerable amount of attention to SMMEs in the past decade by both creating and promoting financial institutions and support organisations to aid these entities to attain their legally imposed objectives.

In more recent times, in South Africa, it is estimated that SMMEs are responsible for employing more than $90 \%$ of the total national workforce and are responsible for contributing up to $50 \%$ to the South African Gross Domestic Product (Booyens, 2011; Africagrowth, 2010). Concurrently, the Department of Trade and Industry (2012) express the view that South African SMMEs are reported to contribute between $52 \%$ and $57 \%$ to Gross Domestic Product, while providing up to approximately $61 \%$ of South African employment opportunities. Despite the contribution of SMMEs, prior research shows that the sustainability of South African SMMEs leaves much to be desired.

\subsubsection{The sustainability of South African SMMEs}

Notwithstanding the legally imposed objectives by local government, SMMEs, in South Africa, are deemed to have one of the worst sustainability rates in the world. Based on the research conducted by Fatoki and Garwe (2010) there is a very strong inverse correlation between the weak South African sustainability rate and the high South African SMME failure rate. This view is supported by Fatoki and Smit (2011) when raising the opinion that $75 \%$ of SMMEs have to close shop after operating on average, for 42 months. This is reiterated by Naidoo (2007) when highlighting that a majority of South African SMMEs fail during their infancy stages, while the remainder fail only a few years after becoming established; after a guesstimated 3 years. In view of the afore-mentioned SEDA (2010) avers that since 2004, a staggering 80\% of South African SMMEs have failed within their first year of trading and, as a result, the South African economy has lost more than R68 million in business opportunities (Mutezo, 2005).

The failure rate of South African SMMEs and the impact thereof on the national economy is extremely severe. In an attempt to identify the root cause of the above dispensation, a number of factors have been investigated to determine their overall influence on SMME sustainability.

\subsubsection{Factors which influence SMME sustainability}

Although South African SMMEs are commended for their significant contribution to both the African continent and the South African economy, prior research suggests that there are quite substantial amounts of limitations which impact adversely on the growth and development of these entities. It is these limitations, which are also strongly believed to contribute significantly towards the weak sustainability rate of South African SMMEs. Booyens (2011) avers that a variety of challenges and constraints are faced by South African SMMEs. These constraints can be categorised as either macroeconomic factors or micro-economic factors. The macro-economic factors according to Kunene (2008) are those factors that exist externally from a business; likely to present situational variables, which may assist or inhibit a business leader during the start-up phase and/or the lifespan of the business. Macro-economic factors cannot be managed easily by a 
business leader because these factors are more often than not, influenced by events that are beyond the control of the business leader herself/himself (Grimsholm \& Poblete, 2010). Against this backdrop, Kadocsa and Francsovics (2011) assert that political situations, economic situations, activities of government, domestic markets, foreign markets, general technical developments, technological developments, taxes, interest rates, monetary policies, inflation and competition, among other, are major macro-economic factors which directly affect SMMEs sustainability.

As opposed to the macro-economic factor is the micro economic factors, which include all business-specific factors that are internally influenced within a business, particularly by a business leader's actions, including the availability of resources, personal skills and abilities, as well as the effective use of both financial and non-financial resources (Kunene, 2008). Kadocsa and Francsovics (2011) believe that unclear corporate strategies and fuzzy market strategies, the lack of a business plan, insufficient capacity utilisation, inadequate capital investments, lack of knowledge on information technology, high employee turnover and poor supplier performance, are major micro economic factors which directly (and adversely) affect small business sustainability. Furthermore, Venter et al. (2003), state that ineffective marketing, insufficient business knowledge and poor financial management are major micro-economic factors that impact SMME sustainability.

In addition to the above, Naidoo (2007) mentions that the lack of managerial skills is one of the most critical factors that adversely influence SMME sustainability as business that cannot be managed will become uncontrollable. Tihomola (2010) supports the latter's view when stating that the lacks of managerial skills will most likely result in inadequate systems of internal controls being implemented and maintained. Fundamentally, the use of internal control systems within any SMME rests in the hands of the SMME leader - having the main responsibility of ensuring that internal controls are strategically positioned to achieve the objectives of their respective SMME. Should management, lack necessary management skills, the implementation of an adequate system of internal controls will culminate in a difficult task to execute properly. This is particularly important since internal controls play a crucial role in the sustainability of any business.

\subsection{An overview of internal controls}

Cascarino and Van Esch (2007) define the term internal control as a process which is developed by relevant stakeholders, within a business, with the main intention to provide reasonable assurance regarding the achievement of three objectives, namely the safeguarding of assets, the integrity and reliability of financial and operational information and compliance with rules and regulations. The core internal controls are greatly affected by all stakeholders within an organisation. COSO (2011) states that in larger organisations, key stakeholders have roles and responsibilities to fulfil, particularly pertaining to internal controls, including the likes of management, the Board of Directors (BODs), the internal audit team and other personnel. Although the aforementioned stakeholders are evidently in larger organisations, similar stakeholders can be found in SMMEs (e.g. management may relate to the SMME leader, while the BODs may relate to investor(s) and/or SMME leader, etc.). The roles and responsibility of the aforementioned stakeholders are explicated below.

Management is entrusted with the responsibility to both design and implement an effective system of internal control. According to Watson (2009) management is responsible for establishing and maintaining a system of internal control, identifying proper internal control frameworks to be used when evaluating internal controls, providing an assessment on the effectiveness of internal controls, and identifying any evident material weaknesses in the existing system of internal control. As embedded in management's day-to-day duties they should not only ensure the optimal utilisation of internal control systems, but also ensure that internal controls are strategically positioned to achieve the objectives of their business, namely fortifying business sustainability.

Notwithstanding the above, Thornton (2009) pinpoints that all employees of a business should be responsible for producing information that can be utilised in their organisation's system of internal control, or should take any other actions which are required to affect internal controls in a broad sense. Furthermore, it is the responsibility of all personnel to ensure that the established policies and procedures to govern business processes are complied with. Of particular significance, Shah (2007) draws attention to the fact that employees should be responsible for conversing with management any problems in operations, non-compliance with the code of conduct or any other policy violations or illegal actions (without having the fear of being 'targeted' as a negative team player). In assisting the aforementioned roleplayers to implement a sound system of internal control in an organisation, and evaluate its effectiveness, it is strongly recommended that several internal control frameworks are consulted to find the "optimum mix" of internal controls which should add the most value in a business setting. 


\subsubsection{Internal control frameworks}

According to Cereola and Cereola (2011) internal control frameworks provide a basis for internal controls in any organisation and is also used to make decisions around the effectiveness of existing internal controls. In addition, such frameworks are useful tools for both management and internal auditors to evaluate and address the adequacy of internal controls in their respective organisation(s) (Cereola \& Cereola, 2011). The internal control frameworks that are of particular importance are that of the COSO internal control framework, COBIT framework and the COCO framework. Each of these frameworks is briefly discussed below:

\subsection{2 coso internal control framework}

The COSO internal control framework was established by the Committee of Sponsoring Organisations of the Treadway Commission (COSO) during the course of 1992. According to COSO (2010), to have internal control processes, there need to be five inter-related elements evident, namely control environment; risk assessment; control activities; information and communication; and monitoring. These five control elements are reported by COSO to be derived from the manner in which management operates within their respective businesses, in a general sense, and are integrated within generic management processes. Based on the works of Larry (2006), these elements collectively help any organisation to accomplish its internal control objectives and, as such, each element should be present in organisations to have some sort of assurance of effective internal controls. Ratcliffe and Landes (2010) express the view that these elements do, in fact, apply to all businesses. However, businesses that are smaller in size (e.g. SMMEs) may implement these elements differently than larger ones. The major reason for the latter is because smaller businesses' internal controls are less formal and less structured than those of larger organisations

\subsubsection{COBIT framework}

According to CPA (2011) SMMEs are not likely to have an Information Technology (IT) department or helpdesk that is fully designed to address its IT related issues. The significant role played by IT in many businesses, has led to the view that IT governance must be managed to support business objectives, and to mitigate risks that are associated with the implementation of IT (Lin, Guan \& Fang, 2010). In view of this, Koornhof (2009) expresses his concern that IT governance is only pertinent to larger organisations when compared to smaller organisations. One should however keep in mind that IT governance is an integral element of every organisation, irrespective of the size as most businesses make use of IT solutions (Writer, 2007). Significantly, IT governance ensures that value is added in a business and that all risks and controls, in terms of IT, are well balanced. Furthermore, effective IT governance ensures that IT supports business objectives, optimises business investment in essential IT, and manages IT-related risks and opportunities appropriately (Ahmad, 2009). Hence, as a result, SMMEs should benefit from the creation of value through the application of IT governance in their day-to-day business operations (Kroonhof, 2009). Albeit the above, IT-related control frameworks, such as the Control Objectives for Information and related Technology (COBIT), amongst other, are directed towards larger organisations, thereby making it difficult for SMMEs to implement due to limited resources of both financial and non-financial nature.

\subsubsection{COCO framework}

The COCO framework was founded by the Canadian Institute of Charted Accountants in 1995. According to the Department of National Treasury (2009), COCO was developed to improve the internal controls and governance in organisations and, most importantly, to provide a basis upon which judgments about the effectiveness of an existing internal control system can be made. QFinance (2011) believes that COCO builds on COSO's internal control framework and is perceived by many as much more concrete and user friendly. There is however, no evidence in research that SMMEs do make use of COCO as an internal control framework to evaluate their existing internal controls. COCO views internal control as a collaboration of elements, namely that of resources, systems, processes, culture, structure and tasks, which support management to achieve business objectives (Department of National Treasury, 2009). According to the International Federation of Accountants (2006) COCO proposed a set of qualitative criteria to evaluate internal controls such as purpose, commitment, capability, monitoring and learning criteria. 


\subsubsection{Barriers to internal control}

Despite the fact that internal controls are of extreme importance, in South Africa, prior research suggests that SMMEs have numerous barriers which prevent them to implement effective systems of internal control. There are many issues pertaining to internal controls in SMMEs, however management's negligence and the lack of emphasis regarding the control environment, information distortion and ineffective supervision seem to be at the top of this list (Jiong \& Li, 2010). The current situation, which affects the majority of small businesses, is that these problems could be attributed to the fact that many internal controls standards, guides and frameworks are mostly geared towards large enterprises as opposed to that of smaller enterprises. The latter will, therefore, make it difficult for SMMEs to adopt such frameworks because of the lack of financial resources and other prevailing issues. The most prevailing barriers to internal controls include: 1) management neglects internal control, 2) prominent problems within the enterprise environment, 3) distortion of accounting information and poor management communication, 4) lack of effective supervision mechanisms, 5) limited funding and limited resources, 6) unusual transactions, 7) intentional disregard of controls, 8) collusion, 9) inadequate use of resources, and 10) unauthorised transactions (Jiong \& Li, 2010; Jackson \& Stent, 2007; CPA, 2008; Fraud Advisory Panel, 2006; Campbell \& Hartcher, 2003; KPMG, 2009; European Federation of Accountants, 2005)

\subsubsection{Consequences of weak internal control}

A strong internal control system should ensure sustained business development (Temkin, 2009). On the contrary, a small business environment with weak internal controls would be susceptible to all types of detrimental risks. The term 'risk', as defined by the IIA, refers to an uncertainty of an event occurring that could have an (adverse) impact on the achievement of business objectives (IIA, 2012). When these risks surface within a small business environment, the overall sustainability of the respective business will become uncertain. A risk which is quite common in a business entity which has weak (inadequate) internal controls is that of irregularities. According to Smit (2010) irregularities include all types of transgressions. A transgression, in turn, is defined as an act of violation of a law, or a duty or moral principle (Wordnetweb, 2010). Of greater importance, and for purposes of this study, transgressions of internal controls include company policies, mission statements, code of ethics, labour agreements, and so on (Smit, 2010). Should a transgression occur and go undetected for a long period of time, the overall sustainability of any business could be hampered.

\subsubsection{Enterprise risk management framework}

In order for SMMEs to effectively respond to risks, which particularly stem from weak or inadequate internal controls, implementation of a vigorous risk management process are believed to be of paramount importance to the sustainability of SMMEs. An effective risk management process represents a process that systematically aims to identify, evaluate and manage business related risks that stem from both internal and external risk factors (Grote \& Moss, 2008). In essence, this means that SMMEs should implement an effective ongoing process to identify risks, measure the potential impact of the risks against probabilities of such risks occurring and, afterwards, generate what (they believe) is an essential activity to proactively manage these risks. Furthermore, the IIA (2010) provide the some recommendations when businesses endeavour to implement an effective risk management process, namely that business objectives should support and align with the business's strategic objectives; significant risks should be identified and assessed; appropriate risk responses that align risk with the business's risk appetite should be selected; and relevant risk information should be captured and communicated in a timely manner across the business, enabling all stakeholders to carry out their responsibilities.

Moreover, the Committee of Sponsoring Organisations developed a risk management framework called Enterprise Risk Management (ERM) Integrated Framework in 2004 (COSO, 2004). The ERM framework was initiated by COSO in order for management to effectively identify, asses and manage risks down to an acceptable level. The IIA (2011) also draws attention to the benefits of implementing COSO's ERM framework, namely there is greater probability of attaining business's objectives; there is a consolidated reporting of disparate risks at board level; there is an improved understanding of the key risks facing the business; there is a greater management focus on risks that really matter; there is more focus internally on doing the right things in the right way; and there is more informed risk-taking and decisionmaking.

\subsection{Research design and methodology}

This research study was empirical in nature, where a real-life phenomenon was investigated by firstly undertaken a 
thorough literature review, after which data were collected to help mitigate and/or solve the problem. The research design for this study followed a descriptive approach as it entailed the description of phenomena that exist in the practical world (Collis and Hussey, 2009). The main intention of this research was to resolve the identified research problem, namely that SMMEs are perceived as not sustainable owing to inadequate utilisation of internal controls. This research fell within the ambit of the positivistic research paradigm. The data collected for this research was aimed to mitigate and/or solve the identified research problem, by means of quantitative research techniques, namely to determine the degree to which the implementation of an adequate system of internal controls can help to improve SMMEs' sustainability. The logical approach, which was undertaken for this research study was that of deductive reasoning, as the initial perception raised by the authors emanated from existing literature. The data collected was furthermore tested by through a thorough quantitative analysis. Moreover the research was as also applied research, as it incorporated quantitative research characteristics in order to provide recommendations and/or other tools which could be used to help solve or mitigate the identified research problem.

More than that, this research was regarded as large scale survey research as data were predominantly collected from .respondents through the means of a questionnaire. The questionnaire used consisted of 16 questions (three openended questions and 13 close-ended questions) and was piloted by three expert researchers and four members of the general public. The targeted population was that of SMME leaders, namely owners and managers, who operated in the fast moving consumer goods industry, that were also actively involved in their respective businesses activities. For the purposes of this research study, non-probability purposive sampling was used to select a representative sample size. The main reasons for the latter were that the actual size of the population was unknown and the authors wanted to glean rich data for analysis-purposes. As a result, the sample size constituted 110 SMME owners and managers.

In order to enhance the richness of data, it was decided that all responses, as provided by respondents, should have adhered to a certain set of delineation criteria, before being regarded as valid, namely respondents had to be regarded as owners and/or mangers in their respective SMMEs; respondents' SMMEs had to operate in the fast moving consumer goods industry; respondents' SMMEs had to be based in the Cape Peninsula; respondents had to be actively involved in their businesses' processes; respondents' SMMEs had to be regarded as non-franchised entities; respondents' SMMEs had to be in existence for at least 1 year; respondents' SMMEs had to satisfy the definition of a SMME as per the National Small Business Act, No. 102 of 1996 and the National Small Business Amendment Act, No. 29 of 2004.

\section{Data Analysis and Discussion of Findings}

From the data analysed, it was found that, $50 \%$ of all respondents were regarded as managers of their respective SMMEs, while $25 \%$ were regarded as owners of their respective SMMEs. The remaining $25 \%$ of respondents were all regarded owners and managers of their respective SMMEs. Of all responses received, it was apparent that $46.8 \%$ of SMMEs, which belonged to respondents, were in existence between 1 year and 5 years, while $28 \%$ of these entities were in existence between 5 years and 10 years. Moreover, 16.8\% of SMMEs were in existence between 10 years and 20 years, and $8.4 \%$ of SMMEs had been in existence for more than 20 years.

\subsection{The control environment of respondents}

An internal control environment is concerned with how much stakeholders at the top of the organisation (management) care about internal controls. To establish how the control environment of SMMEs appear, respondents were asked to rate the importance of certain aspects of the control environment, which were regarded by the authors as the most important aspects for business sustainability (this was done by means of using a 5 point Likert scale of $1=$ 'strongly disagree', $2=$ 'disagree', 3 = 'neither agree or disagree', 4 = 'agree', 5 = 'strongly agree'. The following dispensation emerged in Table1.

Table1: Perception of respondents regarding the control environment of their SMMES

\begin{tabular}{|lc|}
\hline \multicolumn{1}{|c|}{ Important aspects of the control environment } & Agreeableness (\%) \\
Customer satisfaction & $92.5 \%$ \\
Fair and honest dealings with suppliers & $88.8 \%$ \\
Appropriate guidance in performance of jobs & $87.8 \%$ \\
Ethical behaviour within the business & $86.0 \%$ \\
Moral guidance about what is right and wrong & $83.2 \%$ \\
Integrity within the business & $82.2 \%$ \\
\hline
\end{tabular}


Source: Authors' Fieldwork, 2014.

\begin{tabular}{|ll|}
\hline Commitment to competency & $75.7 \%$ \\
Compliance with laws and regulations & $75.7 \%$ \\
Strict adherence to policies and procedures & $72.9 \%$ \\
\hline
\end{tabular}

From the above it is evident that customer satisfaction was rated as the most important aspect of respondents' SMME's control environment; mapping to the fact that the risk of customer dissatisfaction could impact on business sustainability if not well controlled or mitigated. Fair and honest dealings with suppliers arise as the second most important aspect; owing to the fact that bad relationships with suppliers could result in availability concerns, namely products not being made available for trading purposes resulting in loss of revenue opportunities. It is disappointing to note that strict adherence to policies and procedures was rated the least important. Policies and procedures sets the governance foundation and, thus, an environment where policies and procedures are not strictly adhered to or adequately documented could result in personnel operating outside their mandate, therefore exposing the business financial risk; incorrect procedures being followed which could negatively impact on the accuracy and reliability of information; inefficiencies and ineffectiveness; and irregularities or fraud.

\subsection{Implementation of internal controls}

In order to determine which internal controls were implemented by SMMEs respondents were asked to rate specific statements (in terms of levels of agreement) in relation to the internal controls which they had implemented. This was also done by means of a 5 point Likert scale of 1= 'strongly disagree', 2 = 'disagree', 3 = 'neither agree or disagree', $4=$ 'agree', 5 = 'strongly agree'. The statements below, which were categorised as different types of internal controls, are evident in Table 2 below.

Table2: The internal control setup of respondents

\begin{tabular}{|clc|}
\hline Internal control type & \multicolumn{1}{c}{ Statement which was rated } & Agreeableness (\%) \\
& My business has proper authorisation controls & $81.3 \%$ \\
Preventive & Tasks within my business is properly divided & $73.3 \%$ \\
& Financial documents are sequentially numbered & $70.1 \%$ \\
& My business have effective systems of follow-up in place & $79.4 \%$ \\
Detective & My business conducts periodical employee reviews & $70.1 \%$ \\
& My business conduct reconciliation of accounts & $76.7 \%$ \\
& My business constantly compare budgeted figures against actual costs & $77.6 \%$ \\
Directive & My business processes are governed by formalised policies and procedures & $73.8 \%$ \\
& Individual tasks in my business are clearly defined & $82.2 \%$ \\
\hline
\end{tabular}

Source: Authors' Fieldwork (2014).

From the above it is clear that a majority of respondents mostly agreed to the statements regarding internal controls. This translates to the situation that most respondents had implemented different types of internal controls. In addition to the above, it was also important to establish whether respondents deemed these controls of any help in their business, in a holistic manner. As a result, respondents were asked to rate statements pertaining to how helpful their internal controls were in a general sense which were done through means of a 5 point Likert scale of $1=$ 'very unhelpful', $2=$ 'unhelpful', 3 = 'undecided', 4 = 'helpful', 5 = 'very helpful'. The findings made are evident in Table 3 below:

Table 3: Perception of benefits of internal control objectives according to respondents

Source: Authors' Fieldwork (2014).

\begin{tabular}{|lc|}
\hline \multicolumn{1}{|c|}{ Internal control objective } & Helpfulness (\%) \\
Protecting assets & $74.8 \%$ \\
Enhancing productivity & $72.9 \%$ \\
Encouraging good management & $72.0 \%$ \\
Reducing exposure to risks & $70.1 \%$ \\
Detecting errors & $69.2 \%$ \\
Preventing errors & $68.2 \%$ \\
Clarifying business objectives & $64.5 \%$ \\
Ensuring proper financial reporting & $59.8 \%$ \\
\hline
\end{tabular}


From the above it is clear that respondents were indeed aware of the benefits of internal controls with regards to protecting assets, enhancing productivity, encouraging good management and reducing exposure to risks, being rated as the most helpful benefits among other. The latter suggests that the internal controls that are implemented by respondents were helpful, at least, to respondents.

\subsection{Awareness of internal control frameworks}

In an attempt to assess whether respondents implemented their internal controls based on formal internal control frameworks, respondents were asked an open-ended question whether they were aware of any internal control frameworks that are used in practice by businesses. From the data analysed, a mammoth $88.8 \%$ of respondents indicated that they were not aware of any formal internal control frameworks. Respondents who indicated that they were aware of existing internal control frameworks were further asked to list the different internal control frameworks they were aware of through another open-ended question. The following findings emerged as depicted in Figure 1 below.

Figure 1: The awareness of respondents of formal internal control frameworks

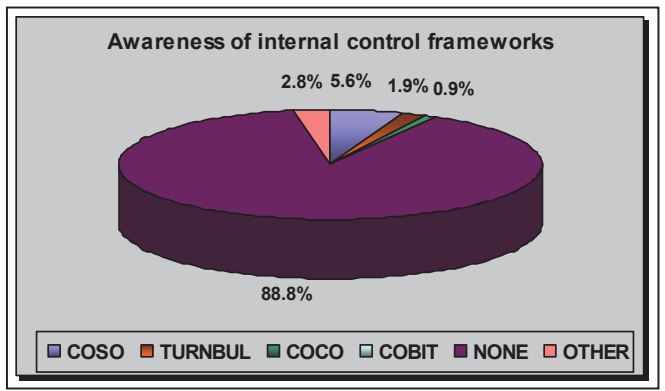

Source: Authors' Fieldwork (2014).

From the above it is evident that only $11.2 \%$ of respondents were aware of existing internal control frameworks. The most popular internal control frameworks were that of COSO (5.6\%); TURNBUL (1.9\%) and COCO (0.9\%). It should also be noted that the other $(2.8 \%)$ specified internal control frameworks pertaining to: CATMAN CAN, combination of COSO and Turnbul, and a combination of COCO, COBIT and Turnbul.

\subsection{Internal control techniques}

Although respondents were mostly unaware of formal internal control frameworks, respondents had to indicate whether they make use of certain internal control techniques (dubbed as "business techniques" in the questionnaire). This was done by asking respondents to rate statement as to how effective certain internal control techniques were to assure business sustainability. This was determined through a 5 point Likert scale of $1=$ 'very ineffective', $2=$ 'ineffective', $3=$ 'neither ineffective nor effective', 4 = 'effective', 5 = 'very effective'. A collaboration of the findings made is provided below in Table 4.

Table 4: The effectiveness of internal control techniques used by respondents

\begin{tabular}{|llc|}
\hline Internal control type & Internal controls "business techniques" & Average Effectiveness (\%) \\
& Physical controls over storage and receiving area & $80.4 \%$ \\
& Management supervision & $77.6 \%$ \\
& Authorisation of payments & $75.7 \%$ \\
Preventative & Appropriate supervision of staff & $75.7 \%$ \\
& Processing of customer complaints & $79.2 \%$ \\
& Access controls over entrances, safes and tills & $74.8 \%$ \\
& Security measures over physical assets & $79.2 \%$ \\
Detective & Assigning of authority levels & $69.2 \%$ \\
& Stock counts & $78.5 \%$ \\
Directive & Reviews of transactions or work performed & $60.8 \%$ \\
& Management directives & $57.0 \%$ \\
& Guidelines on personal use of assets & $54.2 \%$ \\
\hline
\end{tabular}

Source: Authors' Fieldwork (2014). 
From the above it is clear that respondents did, in actual fact, make use of internal control techniques as prescribed by internal control frameworks, in spite of the fact that $88.8 \%$ of respondents had no awareness of formal internal control frameworks. Despite the variety of internal control techniques used, some techniques proved to be much more effective than others. A possible reason for this is that, in essence, SMMEs are exposed to certain limitations or barriers, which have a direct impact on the implementation and overall functioning of their existing system of internal control. In order to test this latter presumption, respondents were also asked through an open ended question, to provide their major limitations in making effective use of internal controls, as well as rate its negative influence on implementing an effective system of internal control. This was determined in the form of a 5 point Likert scale of $1=$ 'very influential', $2=$ 'influential', $3=$ 'average influential', $4=$ 'little influential', $5=$ 'very little influential'. The findings made are tabulated in Table 5 below.

Table 5: Major limitations on the effectiveness of internal controls

\begin{tabular}{|lc|}
\hline Major limitation to internal controls & Negative influence (\%) \\
Limited funding of resources & $78.5 \%$ \\
Management override & $77.6 \%$ \\
Incompetent personnel & $72.9 \%$ \\
Poor management & $69.2 \%$ \\
\hline
\end{tabular}

Source: Authors' Fieldwork (2014).

The above table confirms what was previously discussed under the literature review. It is clear that the availability of funding for SMMEs remains a significant overarching concern which requires immediate intervention. Due to the nature of business operations and the size of SMMEs, it can also be observed that management override presents another knock on effect on the implementation of an effective system of internal controls, as implemented internal controls tend to be circumvented in an environment where management override is an issue. The influence of incompetent personnel and poor management, as noted above, does not only adversely influence on the overall functioning of the system of internal control; but also presents a much bigger sustainability risk; especially for smaller entities.

\subsection{Internal control effectiveness}

Finally, respondents were asked to rate the effectiveness of their existing internal controls by rating certain statements. This was done by asking respondents to provide a rating as to what they used their internal controls for. This was ascertained by means of a 5 point Likert scale of $1=$ 'strongly disagree', 2 = 'disagree', 3 = 'neither agree nor disagree', 4 $=$ 'agree', 5 = 'strongly agree'. The outcome is reflected in Table 6 below:

Table 6: The effectiveness of internal control as per respondents

\begin{tabular}{|lc|}
\hline Use of internal controls & Agreeableness (\%) \\
Performance metrics & $70.1 \%$ \\
Ongoing control monitoring & $70.1 \%$ \\
Time metrics & $70.1 \%$ \\
Control self-assessments & $70.0 \%$ \\
Financial metrics & $69.2 \%$ \\
Performance reviews & $67.2 \%$ \\
\hline
\end{tabular}

Source: Authors' Fieldwork (2014).

From the above it is evident that though internal controls were implemented by respondents, they were not actively used to manage their respective businesses inside-out. Although there were systems of internal control in most SMMEs, the effectiveness of these systems were not in line with what is prescribed by formal internal control frameworks.

\section{Conclusion}

From the above, it is evident that although respondents were aware of internal controls and internal control frameworks as well, and the benefits that can be derived from a successful implementation of internal controls, but the effectiveness of their implementation, in a general sense, were fairly average to say the least. Moreover, it was found that respondents utilise a combination of different types of internal control such as preventive, detective and directive, all of which are 
critical to ensure that a business is well sustained and safeguarded against potential risks. However, enterprise leaders still do not make absolute use of directive controls to further enhance their overall sustainability. Also, some internal controls used were deemed much more effective than others. A possible reason for this dispensation is that these entities are still exposed to certain limitations, which have a direct adverse impact on the implementation and overall functioning of the system of internal control. The authors are of the view that, any system of internal control, which cannot provide a reasonable assurance that business objectives will be met, is a sign of a weak internal control platform, namely weak risk identification processes or risk assessment processes.

Though these enterprises made use of their implemented controls, to a certain extent, all types of internal controls should be maintained, evaluated and monitored on a continuous basis to ensure the adequacy and effectiveness of all internal control processes accordingly. Against this background and also taking into account the fact that the majority of respondents were not aware of the available internal control frameworks, it is conclusive that SMMEs are exposed to the risk that current implemented internal controls cannot effectively prevent, detect and correct as they are not 100\% in line with formal internal control frameworks. As a result, SMMEs could be inadequately safeguarded against risks, which are likely to impact on SMME sustainability.

To remedy the above concerns, the authors are of the perception that respondents should be trained on formal internal control frameworks in order to address the concern of limited awareness of existing internal control frameworks. This can be achieved by outsourcing an external service provider who in turn will provide training and development, which encompasses different types of internal control frameworks, and how to select a framework taking into consideration the size, industry and nature of the business, implementation guidelines, and how the framework can be used to evaluate established internal controls. Furthermore, the training that is received should provide practical examples on how similar businesses have implemented different types of internal controls and how these businesses have actually benefited from its implementation. Ultimately, the transfer of knowledge should be cascaded across the organisation to ensure that relevant information is communicated to all relevant stakeholders. Since the latter intervention might be costly, it is strongly recommended that this is funded by national government; resulting in additional guidance to be provided to aid in the fortification of SMME sustainability.

\section{References}

Africagrowth, 2010. South African Economy and the Role of SMMEs \& SMME awards. [Online]. Available from: http://www.africagrowth.com I2010_SA_SMME_Proposal.pdf [Accessed 21/05/2011].

Aifheli, R. 2012. The impact of performance management on the employee morale in Western Cape Provincial Head Office of Department of Local Government and Housing. A mini thesis submitted in partial fulfilment of the requirements for the degree of Master of Technology: Human Resource Management in the Faculty of Business at the Cape Peninsula University of Technology.

Ahmad, A.A.M.2009. Exploring COBIT Processes for ITG in Saudi Organizations: An empirical Study. The International Journal of Digital Accounting Research, 9(4): February 2009.

AICPA, 2009. Members in Government Guide to Internal Control and Internal Control Services. American Institute of Certified Public Accountants: New York.

Bates, C. 2012. Governance - Misunderstood by SMMEs [Online]. Available from: http://www.ideate.co.za/2012/03/29/governance-\%E2\%80\%93misunderstood-by-smme\%E2\%80\%99s/ [Accessed 01 August 2012].

Berry, A., von Blottnitz, M., Cassim, R., Kesper, A., Rajaratnam, B. \& van Seventer. 2002. The economics of SMMEs in South Africa [Online]. Available from: http://www.tips.org.za/files/506.pdf [Accessed 15/02/2011].

Booyens, I. 2011. Are Small, Medium- and Micro - Sized Enterprieses Engines of Innovation? The reality in South Africa. Science and Public Policy: Bree Tree Publishing Journal, 3(1): February 2011.

Bruwer, J-P. 2010. Sustainability of South African FMGC Retail businesses in the cape peninsula. A dissertation submitted in full fulfilment of the requirements for the degree of Magister Technologiae: Internal Auditing in the Faculty of Business at the Cape Peninsula University of Technology.

Bruwer, J-P, Masama, B., Mgidi, A., Myezo, M., Nqayi, P., Nzuza, N., Phangwa, M., Sibanyoni, S. \& Va, N. 2013. The need for a customised risk management framework for small enterprises Southern African Accounting Association: Conference Proceedings. 26 June 2013.

Bruwer, J-P \& Watkins, J.A. 2010. Sustainability of fast moving consumer goods retail SMMEs. African Journal of Business Management, 4(16):18November 2010.

Campbell, S \& Hartcher, JA. 2003. Internal Controls for Small Business. [Online] Available from: http://www.whistleblowing.com.au/information/documents IInternalControls.pdf. [Accessed 16/02/ 2011].

Cascarino, R. \& Van Esch, S. 2007. Internal Auditing: An Integrated Approach. Lansdowne: Juta.

Cereola, S.J. \& Cereola R.J. 2011. Breach of Data at TJX: An Instructional Case Used to Study COSO and COBIT, with a Focus on Computer Controls, Data Security, and Privacy Legislation. Issues in Accounting Education, 26(3): 521-545, August 2011.

Collis, J. \& Hussey, R. 2009. Business Research: A Practical Guide for Undergraduate \& Post Graduate Students. Palgrave Machmillan.

COSO. 2004. Enterprise Risk Management- Integrated Framework: Executive Summary. [Online]. Available from: http://www theiia.org/iia/ download.cfm?file=9229. [Accessed 18/02/2011].

coso Report, 2006. Internal Control-Integrated Framework. [Online]. Available from: http://www.ruslan.web.id/download/category/1artikel?download $=1 \% 3$ ACOSO [Accessed 21/02/2011].

COSO. 2011. Embracing Enterprise Risk Management: Practical approaches for getting started. [Online] http://www.coso.org/documents/Embracing ERMGettingStartedforWebPostingDec110.pdf [Accessed 16/05/2011]. 
COSO, 2011. Internal Control-Integrated Framework [Online]. Available from: http://www.coso.org /documents/coso_framework_body_v6.pdf [Accessed 30/03/2013].

COSO, 2010. Summary of Internal Control-Integrated Framework by COSO. [Online]. Available from: http://www.coso.org/IC-IntegratedFrameworksummary.htm [Accessed 18/02/2011].

CPA, 2008. Business Management. Internal Control for Small Businesses: 2008 update. [Online]. Available from: http://www.cpaaustralia. com.au/cps/rde/xbcr/cpa-site/internal-controls-for-small-business.pdf [Accessed 22/02/2011].

CPA, 2011.IT Checklist for small business. [Online]. Available from: http://www.cpaaustralia.com.au/cps/rde/xbcr/cpa-site/lT-checklist-small-business2011.pdf. [Accessed 01/11/201].

Deloitte, 2012. Responsibility for internal control. [Online]. Available from:http://www.deloitte.com/view/en_CN/cn/ services/corgov/iclindex.htm [Accessed 08/12/2011].

Department of National Treasury, 2009. Internal Audit Framework [Online]. Available from: http://www.treasury.gov.za/publications/other /Treasury\%20Internal\%20Audit\%20Framework\%20Revised\%202009.pdf. [Accessed 03/02/2012].

Department of Trade and Industry, 2007. Annual review of small business in South Africa 2005 - 2007. [Online] Available from: http:www.trevenna.net/publications/Annual Review.pdf [Accessed 26th May 2011].

Department of Trade and Industry, 2012. Speech delivered by Deputy Minister Elizabeth Thabethe at the launch of Google South Africa Woza Online at the Innovation Hub, Lynnwood, Pretoria [Online] Available from: http://www.dti.gov.za/editspeeches.jsp?id=2320 [Accessed 01 August 2012].

European Federation of Accountants, 2005. How SMEs can reduce the Risk of Fraud: Limiting Fraud Risk - What SMEs can do. [Online] Available from: http://www.fee.be/fileupload/upload/How\%20SMEs\%20can\%20 reduce\%20the\%20Risk\%20of\%20Fraud\%2005117112005121149.pdf [Accessed 3 June 2011].

Fatoki, O. \& Garwe, D. 2010. Obstacles to the growth of new SMEs in South Africa: A principal component analysis approach. African Journal of Business Management, 4(5): 729 - 738, May.

Fatoki, O. \& Smit, V. 2011. Constraints to credit access by new SMEs in South Africa: A supply-side analysis. African Journal of Business Management, 5(4):1413-1425.

Fleak, S.K. Harrison, E.K \& Tuner, A.L. 2010. Sunshine Centre: An Instructional Case Evaluating Internal Controls in a Small Organization. Issues in Accounting Education, 25(4): 709-720, 2010.

Fraud Advisory Panel, 2006. Fighting Fraud: A Guide for SMEs. [Online] Available from: http://www.Fraudadvisorypanel.org/newsite/ PDFs/advice/FightingFraud2ndEdition.pdf. [Accessed 23 June 2011].

Grimsholm, E., \& Poblete, L. 2009. Internal and External factors hampering SME growth - A qualitative case study of SMEs in Thailand. A dissertation submitted in fulfillment of the requirements for the degree of Master in Business Administration: International Management in the Faculty of Socia Sciences at the Gotland University.

Grote, B.K \& Moss, M.A. 2008. How to measure the effectiveness of risk management in engineering design projects? Presentation of RMPASS: a new method for assessing risk management performance and the impact of knowledge management-including a few results. Research in engineering design, 19(2/3): 71-100. 2008.

Hayes, M. 2001. All smiles for SMMEs: The city of Cape Town is pulling out all the stops to encourage the development of SMMEs. The Premier: 52.

IFAC, 2006. Internal Control - A Review of Current Developments. Professional Accountants in Business Committee: Information Paper [Online].Available from: http://www.ifac.org/sites/default/files/publications/files/internal-controls-a-revie.pdf. [Accessed 17/05/2011].

IIA, 2011. Standards for the professional practice of internal auditing.[Online]. Available from: http://www.theiia.org/guidance/standards-andguidancelippf/standards.pdf [Accessed 16/05/2011].

IIA, 2010. 2120 Risk Management. [Online]. Available from: http://www.theiia.org/guidance/standards-and guidance/ippf/standards/standards-items/?i=8269 [Accessed 20/05/2011].

IIA, 2011. COSO Releases New ERM Framework.[Online]. Available from: http://www.theiia.org/guidance/additional-resources/coso-relatedresources/coso-releases-new-erm-framework/. [Accessed 14/01/2012].

IIA, 2012. Standards \& Guidance. [Online]. Available from: https://na.theiia.org/standards-guidance/mandatory-guidance/Pages/Standards-Glossary.aspx [Accessed 5/09/2012].

ISACA, 2007. Knowledge centre: COBIT.[Online]. Available from: http://www.isaca.org/KnowledgeCenter/cobit/Documents/COBIT4.pdf [Accessed 18/01/2012].

Imperial Annual Report. 2011, Risk and opportunies. [Online] Available from: http://www.financialresults.co.za/2011/imperial_2011/ar2011/risks-andopportunities.php [Accessed 20/12/2011].

IT online. 2009. Bleak picture for SA's SMMEs. [Online]. Available from:http://www.it-online.co.za/content/view/945532/ [Accessed 17/02/2011].

Jackson, R.D.C. \& Stent, W.J. 2007. Auditing Notes for South African Students. Audit Education.

Jayathilake. 2012. J.M.B. Risk Management Practices in Small and Medium Enterprises: Evidence from Sri Lanka. African Journal of Business Management, 2(7): July 2012.

Jiong, L. \& Li, X. 2010. Discussions on the Improvement of the Internal Control in SMEs, International Journal of Multidisciplinary Research, 5(9): September 2010.

Kadocsa, G. \& Francsovics, A. 2011. Macro and Micro Economic Factors of Small Enterprise Competitiveness. Acta Polytechnica Hungarica, 8(1): 23-40, 2011.

Kesper, A. 2000. Failing or not aiming to grow? SMMEs and their contribution to unemployment (Published research material cited in terms of the written approval of the office of the Industrial and Policy Research). University of the Witwatersrand, Johannesburg.

Koornhof, F. 2009. A framework for IT governance in small businesses. A dissertation submitted in partial fulfilment of the requirements for the degree of Magister Technologiae: Business Information Systems in the Faculty of Built Environment and Information Technology at the Nelson Mandela University.

KPMG, 2011. Corporate Governance and King 3. [Online]. Available from: http://www.kpmg.com/ZA/en/IssuesAndlnsights/ArticlesPublications/Tax-andLegal Publications/Documents/Corporate\%20Governance\%20and\%20King\%203.pdf [Accessed 23/01/2012].

KPMG Forensic, 2009. Fraud Survey 2008. [Online] Available from: http://www.kpmg.com/AU/en/lssuesAndInsights/ArticlesPublications/Documents/FraudSurvey-2008.pdf [Accessed 30/06/2011].

KPMG Forensic, 2009. Fraud Survey 2009 [Online] Available from: http://www.kpmg.com/ZA/en/lssuesAndlnsights/ArticlesPublications/RiskCompliance/Documents/Fraud\%20Survey.pdf [Accessed 09/07/2011].

Kunene, T. R. 2008. A critical analysis of entrepreneurial and business skills in SMEs in the textile and clothing industry in Johannesburg, South Africa. A dissertation submitted in full fulfilment of the requirement for the degree of Philosophiae Doctor: Entrepreneurship in the Faculty of Economic and 
Management Sciences at the University of Pretoria.

Larry, E.R. 2006. Internal Controls: No Small Matter. Internal Auditor, 63(5):47-51, October 2006.

Lin, F., Guan, L., \& Fang, W. 2010. Critical factors affecting the evaluation of information control systems with the COBIT framework: A study of CPA firms in Taiwan. Emerging Markets Finance \& Trade, 46(1), 42-55. February 2010.

Maree, K. 2007. First Steps in Research. Pretoria: Van Schaik Publishers.

McBride, R. 2008. The impact of fraud and poor internal controls on municipal finances. [Online]. Available from: www.masc.sc/programs I.../riskletter_fail08_singlepages.pdf [Accessed 22/02/2011].

McGill, 2011. Assessment Criteria for Risk - Extracted from Guidance on Control, published by the Criteria of Control Board (COCO). [Online]. Available from: http://www.mcgill.ca/internalaudittools/coco.pdf [Accessed 22/02/2011].

Mutezo, A. T. 2005. Obstacles in the access to SMME finance: an empirical perspective on Tshwane. A dissertation submitted in full fulfilment of the requirement for the degree of Master of Commerce: Business Management in the Faculty of Economic and Management Sciences at the University of South Africa.

Naidoo, R.A. 2007. SMME Sustainability: The Relevance of Production and Operation Skills. Unpublished Master's Thesis. University of Johannesburg, Johannesburg.

NHS Employers, 2012. Employment history and reference checks. [Online]. Available from:http://www.nhsemployers.org/Aboutus/Publications /Documents/Employment\%20history.pdf [Accessed 30/04/2013].

Palfi, C.2009. Control environment in banking system: an empirical study on Romanian framework vs. COSO and CoCo models. International Journal of Business Research Publisher: International Academy of Business and Economics, 9(1): 01 February 2009.

Petrovits, C., Shakespeare, C. \& Shin, A. 2009. The Causes and Consequences of Internal Control Problems in Nonprofit Organizations (unpublished research material). New York University Stern School of Business, New York.

Putra, 2009. Effective Internal Controls for Small Medium businesses. [Online]. Available from: http://accounting-financial-tax.com/2009/04/effectiveinternal-control-for-small-medium-business/ [Accessed 22/02/2011].

Puttick, G. \& Van Esch, S. 2007. The Principles and Practice of Auditing. Cape Town: Juta.

PriceWaterHouseCooper, 2011. King 3 Boards and Directors. [Online]. Available from: http://www.pwc.com/za/en/ki ng3/boards-and-directors/index.jhtmll [Accessed 23/01/2012].

QFinance, 2011. Internal control frameworks: COSO, COCO, and UK Corporate Governance Code. [Online].Available from: http://www.qfinance.com/corporate-governance checklists/internal-control-frameworks-coso-coco-and-the-uk-corporate-governance-code.pdf. Accessed 18/09/2011].

Ratcliffe, A \& Landes, E. 2010. Understanding Internal Controls and Internal Controls services. [Online]. Available from: http://media.journalofaccountancy.com /JOA/lssues/2009/09/Understanding_Internal_Control_Services_2.pdf [Accessed 18/02/2011].

Saunders, M.N.K, Lewis, P \& Thornhill, A. 2007. Research Methods for Business Studies.Pitman Publishing.

SEDA, 2010. Seda technology programme incubators fast track SMME success. [Online].Available from: http://www.seda.org.za/Happening /LatestNews/PressReleases/Pages/Seda-technology-programme-incubators-fast-track-SMME-success.aspx.[Accessed 17/02/2011].

Shah, A. 2007. Local Public Financial Management. World Bank Publication.

Smit, Y. 2010. Internal Control \& COSO's Control Framework. Internal Auditing notes compiled at Cape Peninsula University of Technology, South Africa.

Smit, Y. 2010. Irregularities $-3^{\text {rd }}$ year notes (for revision in $4^{\text {th }}$ year). Internal Auditing notes compiled at Cape Peninsula University of Technology, South Africa.

Smit, Y \& Watkins, J.A. 2012. A literature review of small and medium enterprises (SME) risk management practices in South Africa, AJBM 6 (21):6324 6330.

Solomon, G. 2004. Entrepreneurship and impact of entrepreneurial orientation training on SMMEs in the South African context: A longitudinal Approach (Magister Commerce). Unpublished Master's Thesis. University of the Western Cape, Cape Town.

South Africa. 1996. National Small Business Act, No. 102 of 1996. Pretoria: Government Printer.

South Africa. 2004. National Small Business Amendment Act, No. 29 of 2004. Pretoria: Government Printer.

Spafford, G. 2005. Enterprises Should Emphasize Preventative Controls. [Online]. Available from: http://www.itsmwatch.com/itil/article.php /3524221/EnterprisesShould-Emphasize-Prevantative-Controls.pdf [Accessed 18/02/2011].

Temkin, S. 2009. Auditors must attest to Internal Controls. Business Day. September. 29,1.

Teketel, T. \& Berhanu, Z. 2009. Internal Controls in Swedish Small and Medium Size enterprises. A dissertation submitted in full fulfilment of the requirement for the degree of Masters in Business Administration at the University of Umea.

Tihomola, S.J. 2010. Perceptions of Small, Medium, and Micro Enterprise Entrepreneur regarding Factors Contributing to Failure: A Case of Tshwane Metropolitan Municipality. Unpublished Masters mini Thesis, Department of Management and Entrepreneurship. Tshwane University of Technology.

The International Federation of Accountants, 2004. International Standards on Auditing 240 (Revised): The Auditor's Responsibility to Consider Fraud in an Audit of Financial Statements. [Online]. Available from: http://www.kpmg.ky/uploads/ky/2004\%20ISA\%20240.pdf. [Accessed 30 June 2011].

The International Federation of Accountants, 2006. Internal Controls - A Review of Current Developments. [Online]. Available from: http://www.ifac.org/sites/default/files/publications/files/internal-controls-a-revie.pdf [Accessed 5 October 2012].

Thornton,G.2009. Monitoring the system of internal control. [Online] Available from: http://www.boardoptions.com/monitoringinternalcontrol.pdf Accessed 08/12/2011].

UCT, 2010. UCT Study Shows Recession Has Hit SA Entrepreneurship Hard. [Online]. Available from: http://www.gsb.uct.ac.za/files /CapeBusinessNews14May10.pdf [Accessed 01/08/13]

Vallabhaneni,S.R. 2005. Wiley CIA Exam Review, Internal Audit Activity's Role in Governance, Risk. John Wiley and Sons.

Viviers, S \& Venter, D. 2008. Fraud: An SMME Perspective. SAJESBM NS, 1(1): 51-65.

Weiss, M \& Solomon, G.M. 2010. Auditing It Infrastructures for Compliance. Sudbury, Jones \& Bartlett Learning.

Wordnetweb. 2010. Transgression definition. [Online]. Available from: http://wordnetweb.princeton.edu/per//webwn?s=transgression [Accessed 24/02/2011].

Writer, S. 2007. Survey by KPMG. [Online]. Available from: http://securities.stoneford.edu /newsarchive/2007/20071213_headline104926_writer.htmc [Accessed 23/02/2]. 